\title{
Laktoperoksidaz Enziminin Sülfamat Türevleri Bileşikleri Üzerine İnhibisyon Profili
}

\author{
Hande Usanmaz $^{1 *}$, Ufuk Atmaca ${ }^{2}$ \\ ${ }^{1}$ Sinop Üniversitesi, Sağlık Hizmetleri Meslek Yüksek Okulu, Tıbbi Laboratuvar Teknikleri, Sinop, Türkiye (ORCID: 0000-0003-3851-9601) \\ ${ }^{2}$ Atatürk Üniversitesi, Oltu Meslek Yüksek Okulu, Erzurum, Türkiye (ORCID: 0000-0002-5598-0443)
}

(Illk Geliş Tarihi 10 Temmuz 2020 ve Kabul Tarihi 7 Aralık 2020)

(DOI: 10.31590/ejosat.767395)

\begin{abstract}
ATIF/REFERENCE: Usanmaz, H., \& Atmca, U. (2020). Laktoperoksidaz Enziminin Sülfamat Türevleri Bileşikleri Üzerine İnhibisyon Profili. Avrupa Bilim ve Teknoloji Dergisi, (20), 746-750.

$\ddot{O} z$

Sülfamat iskeleti içeren birçok doğal ürün ve ilaç etken maddelerinde bulunmaktadırlar. Son zamanlarda, sülfamatlar bileşiklerinin bulundurdukları fonksiyonel gruplarından dolayı malzeme bilimcisi ve farmakolog tarafından daha fazla ilgi görmektedirler. Peroksidazlar (POD), metabolik fonksiyonlarından dolayı gıda ve ilaç endüstrisinde enzimatik reaksiyonlarda ve klinik teşhislerde önemli kullanım alanında yer alırlar. Laktoperoksidaz (LPO, EC 1.11.1.7) peroksidaz ailesinin bir üyesidir. Bu enzim sütte, tükürükte ve gözyaşında bulunan bir oksidoredüktaz olup, patojen mikroorganizmalara karşı yeni doğanların bağırsak sistemlerini ve meme bezlerini korumada önemli bir role sahip olmaktadır. Memeli sütlerinden edilen LPO enzimi, bakterilerin büyümesinin baskılanmasında ve bakteri inhibisyonunun desteklenmesinde oldukça önemlidir. Sığır LPO'sunun bakteriyal büyümeyi inhibe etmesi, H2O2 ve tiyosiyanat içeren peroksidaz sistemine atfedilir. Bu sistemin antimikrobiyal etkisi sütte doğal olarak oluşmuştur. LPO enzimi üzerine yapılan antibakteriyal çalışmalarda LPO-tiyosiyanat ve peroksit sisteminin patajonik bakterilerde önemli derecede inhibisyona sebep olduğu tespit edilmiştir. LPO’nun birçok uygulama alanı vardır. Peroksidazlar hem gıdalarda hem de farmakolojik uygulamalarda koruyucu olarak kullanılır ve süt işleme tesislerinde nakil esnasında sütün muhafazası amacıyla süt endüstrisinde kullanılmaktadır. Bu çalışmanın amacı, LPO enzimi üzerine Metil benzoilsülfamat, Metil (2-bromobenzoil) sülfamat, Metil (3-fenilpropanoil) sülfamat, Metil (1-naphthoil) sülfamat, Metil (2-metilbenzoil) sülfamat, Metil (2-iyodobenzoil) sülfamat, Metil (2-fenilbutanoil) sülfamat, Metil (4-isopropilbenzoil) sülfamat, Metil (4-metoksibenzoil) sülfamat ve Metil (isoquinoline-1-karbonil) sülfamat bileşilklerinin in vitro etkilerini belirlemektir. Bu sülfamat türevi bileşiklerinin LPO enzimi üzerindeki inhibisyon etkisini belirlemek için, enzim aktiviteleri ölçülerek her bir inhibitör için Lineweaver-Burk grafikleri çizildi; Ki sabiti ve inhibisyon tipleri bu çizilen grafiklerden bulnunarak hesaplanıldı. Ki değerleri sırasıyla Metil benzoilsülfamat $0,70 \mu \mathrm{M}$, Metil (2-bromobenzoil) sülfamat 0,025 $\mu \mathrm{M}$, Metil (3-fenilpropanoil) sülfamat $0,018 \mu \mathrm{M}$, Metil (1-naphthoil) sülfamat $0,047 \mu \mathrm{M}$, Metil (2-metilbenzoil) sülfamat 0,043 $\mu \mathrm{M}$, Metil (2-iyodobenzoil) sülfamat $0,19 \mu \mathrm{M}$, Metil (2-fenilbutanoil) sülfamat 0,39 $\mu \mathrm{M}$, Metil (4-isopropilbenzoil) sülfamat 0,42 $\mu \mathrm{M}$, Metil (4-metoksibenzoil) sülfamat $0,078 \mu \mathrm{M}$, Metil (isoquinoline-1-karbonil) sülfamat $0,075 \mu \mathrm{M}$ olarak belirlendi. Metil (4-isopropilbenzoil)sülfamat bileşiği yarışmasız inhibisyon ve diğer maddeler yarışmalı inhibisyon gösterdiği kaydedildi. Metil (2-metilbenzoil)sülfamat bileşiği ise en etkili inhibitör özelliğini yarışmalı inhibisyon tipi LPO enzimi üzerine $0.018 \pm 0.024 \mu \mathrm{M}$ Ki değeri ile göstermiştir.
\end{abstract}

Anahtar Kelimeler: Enzim inhibisyonu, laktoperoksidaz, memeli sütleri, sülfamat

\section{Inhibition Profile of Lactoperoxidase Enzyme on Sulfamate Derivatives}

\begin{abstract}
They are found in many natural products and active ingredients that contain a sulfamate skeleton. Recently, due to the functional groups of sulfamates compounds, they have received more attention from the material scientist and pharmacologist. Due to their metabolic functions, peroxidases (POD) are important in enzymatic reactions and clinical diagnoses in the food and pharmaceutical industry. Lactoperoxidase (LPO, EC 1.11.1.7) is a member of the peroxidase family. This enzyme is an oxidoreductase found in milk, saliva and
\end{abstract}

* Sorumlu Yazar: Sinop Üniversitesi, Sağlık Hizmetleri Meslek Yüksek Okulu, Tıbbi Laboratuvar Teknikleri, Sinop, Türkiye, ORCID: 0000-00033851-9601, husanmaz@sinop.edu.tr 
tears and has an important role in protecting the gut systems and mammary glands of newborns against pathogenic microorganisms. The LPO enzyme from mammalian milk is very important in suppressing the growth of bacteria and promoting bacterial inhibition. Inhibition of bacterial growth of bovine LPO is attributed to the peroxidase system containing $\mathrm{H} 2 \mathrm{O} 2$ and thiocyanate. The antimicrobial effect of this system occurs naturally in milk. In antibacterial studies on LPO enzyme, LPO-thiocyanate and peroxide system has been found to cause a significant inhibition of pathogenic bacteria. LPO has many application areas. Peroxidases can be used as preservatives in both food and pharmacological applications, and are used in the milk industry for milk preservation during transport in milk processing plants. The aim of this study is to determine the in vitro effects of Methyl benzoylsulfamate, Methyl (2-bromobenzoyl) sulfamate, Methyl (3-phenylpropanoyl) sulfamate, Methyl (1-naphthoyl) sulfamate, Methyl (2-methylbenzoyl) sulfamate, Methyl (2iodobenzoyl) sulfamate, Methyl (2-phenyl), Methyl (4-isopropylbenzoyl) sulfamate, Methyl (4-methoxybenzoyl) sulfamate and Methyl (isoquinoline-1-carbonyl) sulfamate compounds on LPO enzyme. To determine the inhibition effect of these sulfamate derivative compounds on the LPO enzyme, Lineweaver-Burk plots were drawn for each inhibitor by measuring enzyme activities; Ki constant and inhibition types were calculated from these plotted graphs. Ki values were determined as Methyl benzoylsulfamate $0.70 \mu \mathrm{M}$, Methyl (2-bromobenzoyl) sulfamate $0.025 \mu \mathrm{M}$, Methyl (3-phenylpropanoyl) sulfamate $0.018 \mu \mathrm{M}$, Methyl (1-naphthoyl) sulfamate $0.047 \mu \mathrm{M}$, Methyl (2-methylbenzoyl) sulfamate $0.043 \mu \mathrm{M}$, Methyl (2-methylbenzoyl) sulfamate $0.043 \mu \mathrm{M}$-Iodobenzoyl) sulfamate $0.19 \mu \mathrm{M}$, Methyl (2-phenylbutanoyl) sulfamate $0.49 \mu \mathrm{M}$, Methyl (4-isopropylbenzoyl) sulfamate $0.42 \mu \mathrm{M}$, Methyl (4-methoxybenzoyl) sulfamate $0.078 \mu \mathrm{M}$, Methyl (isoquinoline-1-carbonyl) sulfamate $0.075 \mu \mathrm{M}$, respectively. Methyl (4-isopropylbenzoyl) sulfamate compound was noted to exhibit non-competitive inhibition and other substances showed competitive inhibition. Methyl (2-methylbenzoyl) sulfamate compound, on the other hand, showed its most effective inhibitory feature on competitive competitive inhibition type LPO enzyme with a value of $\mathrm{Ki} 0.018 \pm 0.024 \mu \mathrm{M}$.

Keywords: Enzyme inhibition, lactoperoxidase, mammalian milk, sulfamate

\section{Giriş}

Sülfamat grupları birçok doğal ürün ve ilaç molekülleri de bulunmaktadır (Ilardi et al. (2014)). Örneğin, 5'-O- (N-isoleucil) sülfamoil nükleosid türevleri antibakteriyel aktiviteye sahiptirler (Peterson et al. (1992)). Sülfamat grubu içeren Avasimibe ateroskleroz ve hiperlipidemi tedavisinde kullanılmaktadır (Llaverias et al. (2003)). Ayrıca, sülfamat grupları amid, karbamat ve sülfonamid için yararlı bir biyoizosterik ikame görevi görebilmektedir (Albright et al. (1983)).

Biyolojik sistemlerin katalizörleri olan enzimler kimyasal dönüşümleri sağlayan protein yapısında moleküllerdir. İnsan genomunun büyük bir kısmı enzimlerin şifrelerini bulundurur (Lehninger, (2005)). Enzimlerin en önemli fonksiyonları katalitik güçleri ve spesifik olmalıdır. Birçok enzimin aktiviteleri spesifik moleküllerin ve iyonların bağlanmasıyla inhibe edilebilir. Enzimlerin biyolojik sistemlerde inhibe olması kontrol mekanizmasıdır. Ayrıca birçok ilaç toksik moleküller enzimleri inhibe edebilirler. (Berg et al. (2014)). Canlı hücrelerde metabolik reaksiyonların yürüyebilmesi için, serbest radikallere ve oksijen metabolizmasının toksik etkilerine karşı korunması gerekir. Bu koruma sisteminin başında, süperoksitdismutaz, katalaz, glutatyon peroksidaz, glutatyon redüktaz, proteazlar, fosfolipaz ve peroksidazlar gibi antioksidan enzimler ve tokoferol, ubikinon gibi antioksidan moleküller etkilidir. Antioksidan enzim ve moleküller aerobik hücrelerde lipid peroksidasyonu ve diğer serbest radikal aracılı reaksiyonları inhibe ederek hücreleri oksidatif strese karşı korurlar. Antioksidanlar, lipit peroksidasyonu gibi çoğu kronik hastalığın ilerlemesine engel olurlar (Gülçin et al. (2010a)).

Peroksidazlar (POD: H2O2 - Oksidoredüktaz E.C.1.11.1.7), oksidoredüktaz enzimleridir. Metabolizma sırsında oluşan reaktif oksijen türleri enzimler sayesinde zararsız moleküllere dönüşürler (Davies, (1995); Champe et al. (2007)). Peroksidazlar antioksidan özellik göstererek elektron alıcısı olarak hidrojen peroksiti kullanan organik ve inorganik substratların aralarında gerçekleşen oksidasyonu katalizlerler (Hussain et al. (1995)). Peroksidazlar çok yaygın olarak prokaryotlarda, ökaryotlarda ve fotosentetik hücrelerde bulunurlar. (Van Huystee, (1987)).
Memelilerdeki peroksidaz enzimleri; sütte, tükürük bezlerinde ve göz yaşında; LPO (Kumar and Bhatla, (1995)), lökositlerde, trombositlerde, karaciğerde ve dalakta; miyeloperoksidaz, uterus, akciğer duvarlarında, sitoplazma ve mitokondrilerde; glutatyon peroksidaz, mikrozomlar ile lizozomlarda; peroksidazlar lokalize olmuştur (Pütter and Becker, (1987)).

Peroksidaz ailesinin bir üyesi olan Laktoperoksidaz (LPO, E.C. 1.11.1.7), inek ve insan sütünün normal bir bileşenidir. Memelilerin süt, tükrük ve gözyaşı bezleri ile bunlara ait salgilarda bulunmakta ve hem kimyasal hem de immünolojik olarak benzer özellikler göstermektedir. Patojen mikroorganizmalara karşı yeni doğanların bağırsak sistemlerini ve meme bezlerini korumada önemli bir role sahiptir (Kumar and Bhatla, (1995)).

LPO enzimi \% 8-10 karbonhidrattan oluşan bir glikoproteindir. LPO bazik bir proteindir ve izoelektrik $\mathrm{pH}$ değeri 9,2'dir (Kussendrager and van Hooijdonk, (2000)). LPO, 612 amino asit kalıntısı, tek bir hem protez grubu, dört veya beş karbonhidrat zinciri içeren tek bir polipeptid zincirinden oluşur (Paul et al.1985) ve yaklaşık 78 kDa molekül ağırlığı ile toplam kütlenin yaklaşık \% 10'unu oluşturur. (Elagamy et al. (1992); Reiter and HaÈrnulv, (1984); Sisecioglu et al. (2010)). Katalitik merkezdeki hem grubu protoporfirin IX dur ve polipeptid zincirine disülfid köprüsü boyunca kovalent olarak bağlanmıştır (Thanabal and La Mar, (1989)). LPO enzimindeki demir bileşimi $0,07 \%$ dir (Booth et al. (1989)).

LPO, tiyosiyanatı, hipotiyosiyanata okside etmek için, hidrojen peroksitten yararlanan, çeşitli anatomik kısımlarda aktive olur (Paul et al. (1985)). Psödohalojenler, tiyosiyanatlar veya halojenler, enzim için bu gibi antimikrobiyal etkileri gösteren ikinci substratlar olarak işlev görürler (Reiter and Perraudin, (1991)). Bu enzim üzerine yapılan antibakteriyal çalışmalarda LPO-tiyosiyanat ve peroksit sisteminin patajonik bakterilerde önemli derecede inhibisyona sebep olduğu tespit edilmiştir (Jacob et al. (1998)). Bu sistemin aktivasyonu iki reaksiyon maddesinin tiyosiyanat ve hidrojen peroksit konsantrasyonuyla orantılıdır ve antimikrobiyal etkisi sütte doğal olarak oluşur. LPO hidrojen peroksit varlığında, tiyosiyanatın antibakteriyel özelliklere sahip hipotiyosiyanata dönüşmesini katalize eder (Haddain et al. (1996)). 
$\mathrm{SCN}^{-}+\mathrm{H}_{2} \mathrm{O}_{2}$

$\mathrm{OSCN}^{-}+\mathrm{H}_{2} \mathrm{O}$

LPO enziminin birçok bakteri ve mantar suşunu yok ettiğ bilinmektedir (Gulcin et al., 2006). LPO enzimi geniş bir antifungal aktivite gösterir (Jacob, (1998); Sisecioglu, (2009)). Mastit memelilerde bakteri inflamasyonudur. Birkaç antibakteriyel ve antifungal suş üzerinde farklı konsantrasyonlarda tiyosiyanat- $\mathrm{H}_{2} \mathrm{O}_{2}$ maddesinin etkileri, bu süt endüstrisi sorununu çözmek için incelenmiştir (Uguz and Ozdemir, (2005); Sisecioglu (2010)). LPO enziminin, tiyosiyanat$\mathrm{H}_{2} \mathrm{O}_{2}$ sistemi ile gerçekleşen bu reaksiyon sitoplazmik membranı etkileyerek enzimlerin aktivitelerini inhibe ederek ve bakteriyel büyümeyi hücre zarlarına zarar vererek azaltabilirler (Sharma, et al., (2013)).

LPO enziminin biyolojik önemi, mikroorganizmaların istilasına karşı doğal bir koruma sistemi içermesi, hayvan hücrelerini çeşitli zararlar ve peroksidatif etkilere karşı koruması olarak belirlenmiştir (Reiter and HaĖrnulv, 1984; Wolfson and Sumner, 1993). LPO enzimi, yenidoğan bebeklerinin sindirim sistemindeki patojen mikroorganizmalara karşı savunma sisteminin önemli bir rol oynar. $\mathrm{Bu}$ enzim memelilerin immün olmayan biyolojik savunma sisteminin doğal bir bileşeni olup, tiyosiyanat iyonunun antibakteriyel hipotiyosiyanata oksidasyonunu katalize eder (Kumar and Bhatla, 1995).

Bu çalışmada LPO enzimi üzerine, yaygın olarak antioksidan gıda katkı maddeleri, ön ilaçlar veya ilaçlar olarak kullanılan sülfamat türevi maddelerin LPO üzerindeki inhibitör etkilerini araştırması amaçladı. Bu sülfamat türevi maddeleri, önemli biyoaktif bileşiklerdir ve bunlar çeşitli farmakolojik faaliyetlerle ilişkilendirilirler. $\mathrm{Bu}$ amaçla LPO enzimi çeşitli memeli sütlerinden saflaştırılmış, daha sonra bu sülfamat türevi maddeler için IC50 değerleri, $\mathrm{Ki}$ sabitleri ve inhibisyon tipleri belirlenmiștir.

\section{Materyal ve Metot}

Sülfamat türevi maddeler grubumuz tarafindan literatürdeki gibi sentezlenmiştir (Atmaca, (2019)). LPO enzimi ticari olarak satın alındı.

\subsection{Laktoperoksidaz Aktivitesinin Ölçümü}

Aktivite ölçümü, $\mathrm{H}_{2} \mathrm{O}_{2}$ tarafindan 2,2'-azino-bis(3etilbenztiazolin-6-sulfonik asit) (ABTS) kromojenik substratın yükseltgenmesi ve oluşan renkli bileşiğin meydana getirdiği absorbans artısıııın 412 nm'de izlenmesi esasına dayanır (Shindler and Bardsley, (1975)).

LPO

$\begin{array}{ll}\mathrm{H}_{2} \mathrm{O}_{2}+\mathrm{ABTS}^{\bullet+} \longrightarrow & 2 \mathrm{H}_{2} \mathrm{O}+\mathrm{ABTS}^{+} \\ \text {(İndirgenmiş form) } & \text { (Yükseltgenmiş form) }\end{array}$

Aktivite tayininde şu prosedür takip edildi: $3 \mathrm{~mL}$ 'lik spektrofotometre küvetine $2.8 \mathrm{~mL} 1 \mathrm{mM}$ ABTS ve $0.1 \mathrm{~mL} 3.2$ $\mathrm{mM} \mathrm{H}_{2} \mathrm{O}_{2}$ pipetlendi. $0.1 \mathrm{~mL}$ enzim çözeltisi ilave edilerek, küvet alt üst edildikten sonra spektrofotometreye yerleştirilerek köre karş1 412 nm'de absorbans artışı, 3 dakika süreyle her 60 saniyede bir olmak üzere kaydedildi. Kör olarak enzim çözeltisi yerine 0.1 $\mathrm{M}$ fosfat tamponu $\mathrm{pH}=6,0$ konularak diğer çözeltiler aynı oranda kullanıldı. Aktivite hesabında 1 dakikalık absorbans artıșı esas alınmıştır.

\section{2. İn Vitro İnhibisyon Araștırmaları}

Sabit substrat konsantrasyonunda (ABTS) 5 farklı inhibitör konsantrasyonunda her bir inhibitör için aktivite değerleri hesapland1, \%Aktivite ve buradan \%50 inhibisyona sebep olan inhibitör konsantrasyonu değerleri IC50 çalışıldı. Daha sonra 5 farklı sabit substrat konsantrasyonun da ve her bir inhibitör için 3 farklı sabit inhibitör konsantrasyonlarında Linewaver-Burk grafikleri yardımıyla Ki değerleri tespit edildi.

\section{Araştırma Sonuçları ve Tartışma}

Sülfamat bileşikleri, sülfon grubuna bir amino ve bir -OR grubunun bağlı olduğu biyolojik aktiviteye sahip bileşiklerdir (Hartwig 1998). İhtiva ettikleri bu gruplar ilaç olma özelliği kazandırmakta ve günümüzde anti-kanser tedavisinde, antiflemetuar, antibakteriyel, antiviral vb. kullanılan ilaçların yapılarında bulunduğu bilinmektedir (Goddard-Borger ve Stick, (2007); Atmaca, (2020)). Bu sebeple sülfamat bileşikleri hem sentetik farmasötik kimya alanında hem de kullanım alanları bakımından mekanistik organik kimya alanında oldukça önemli bir yere sahiptirler (Daryadel ve ark., (2018)). Bununla birlikte, sülfamat türevi bileşikler LPO enzim aktivitesi üzerindeki etkisi bilinmemektedir. LPO üzerine bu maddelerin inhibisyon etkileri incelenmiştir (Çizelge 1).

Çizelge 1. Sülfamat türevi bileşiklerinin LPO enzim inhibisyon etkisi

\begin{tabular}{|c|c|c|c|}
\hline & $\begin{array}{c}\text { IC50 } \\
\text { Değeri } \\
\text { nM }\end{array}$ & $\begin{array}{c}\text { Ortalama Ki } \\
\text { sabiti nM }\end{array}$ & $\begin{array}{l}\text { İnhibisyon } \\
\text { türü }\end{array}$ \\
\hline $\begin{array}{c}\text { Metil } \\
\text { benzoilsülfamat }\end{array}$ & $\begin{array}{l}0,70 \\
\mu \mathrm{M}\end{array}$ & $\begin{array}{c}0,70 \pm 0,070 \\
\mu \mathrm{M}\end{array}$ & Yarışmalı \\
\hline $\begin{array}{c}\text { Metil (2- } \\
\text { bromobenzoil) } \\
\text { sülfamat }\end{array}$ & $\begin{array}{c}0,025 \\
\mu \mathrm{M}\end{array}$ & $\begin{array}{c}0,025 \pm 0,050 \\
\mu \mathrm{M}\end{array}$ & Yarışmalı \\
\hline $\begin{array}{c}\text { Metil (3- } \\
\text { fenilpropanoil) } \\
\text { sülfamat }\end{array}$ & $\begin{array}{c}0,018 \\
\mu \mathrm{M}\end{array}$ & $\begin{array}{c}0,018 \pm 0,0041 \\
\mu \mathrm{M}\end{array}$ & Yarışmalı \\
\hline $\begin{array}{c}\text { Metil (1- } \\
\text { naphthoil) } \\
\text { sülfamat }\end{array}$ & $\begin{array}{c}0,047 \\
\mu \mathrm{M}\end{array}$ & $\begin{array}{c}0,047 \pm 0,0060 \\
\mu \mathrm{M}\end{array}$ & Yarışmalı \\
\hline $\begin{array}{c}\text { Metil (2- } \\
\text { metilbenzoil) } \\
\text { sülfamat }\end{array}$ & $\begin{array}{c}0,043 \\
\mu \mathrm{M}\end{array}$ & $\begin{array}{c}0,043 \pm 0,0052 \\
\mu \mathrm{M}\end{array}$ & Yarışmalı \\
\hline $\begin{array}{c}\text { Metil (2- } \\
\text { iyodobenzoil) } \\
\text { sülfamat }\end{array}$ & $0,19 \mu \mathrm{M}$ & $\begin{array}{c}0,19 \pm 0,0404 \\
\mu \mathrm{M}\end{array}$ & Yarışmalı \\
\hline $\begin{array}{c}\text { Metil (2- } \\
\text { fenilbutanoil) } \\
\text { sülfamat }\end{array}$ & $0,39 \mu \mathrm{M}$ & $\begin{array}{c}0,39 \pm 0,085 \\
\mu \mathrm{M}\end{array}$ & Yarışmalı \\
\hline $\begin{array}{l}\text { Metil (4- } \\
\text { isopropilbenzoil } \\
\text { ) sülfamat }\end{array}$ & $0,42 \mu \mathrm{M}$ & $\begin{array}{c}0,42 \pm 0,382 \\
\mu \mathrm{M}\end{array}$ & Yarışmasız \\
\hline $\begin{array}{c}\text { Metil (4- } \\
\text { metoksibenzoil) } \\
\text { sülfamat }\end{array}$ & $\begin{array}{c}0,078 \\
\mu \mathrm{M}\end{array}$ & $\begin{array}{c}0,078 \pm 0,0422 \\
\mu \mathrm{M}\end{array}$ & Yarışmalı \\
\hline $\begin{array}{c}\text { Metil } \\
\text { (isoquinoline-1- } \\
\text { karbonil) } \\
\text { sülfamat }\end{array}$ & $\begin{array}{c}0,075 \\
\mu \mathrm{M}\end{array}$ & $\begin{array}{c}0,075 \pm 0,024 \\
\mu \mathrm{M}\end{array}$ & Yarışmalı \\
\hline
\end{tabular}


Sonuçlardan da görüleceği üzere (Çizelge 1) Metil benzoilsülfamat, Metil (2 bromobenzoil) sülfamat, Metil (3fenilpropanoil) sülfamat, Metil (1-naphthoil) sülfamat, Metil (2metilbenzoil) sülfamat, Metil (2-iyodobenzoil) sülfamat, Metil (2fenilbutanoil) sülfamat, Metil (4-isopropilbenzoil) sülfamat, Metil (4-metoksibenzoil) sülfamat ve Metil (isoquinoline-1karbonil) sülfamat bileşikleri için en küçük IC50 ve Ki değerleri Metil (3-fenilpropanoil) sülfamat için elde edilmiştir. Sülfamatlar biyoaktif bileşiklerin önemli grubunu oluşturmaktadır. Sülfamatlar antioksidan davranışına ve potansiyel sağlıkla ilgili yararına artan ilgi vardır. Fakat yürütülen bazı çalışmalarda sülfamat bileşiklerin çeşitli zararlı etkileri belirtilmiştir. Sülfamat içeren besinleri tüketirken dikkatli olmalıyız, çeşitli çalışmalarla gösterilmiştir ki bu moleküllerin farklı enzimler üzerine etkisi vardır.

Bazı sülfamat maddelerin enzim aktivitesi üzerindeki önleyici etkileri in vitro şartlar altında test edildi; $\mathrm{IC}_{50}$ değerleri aktivite \% - [inhibitör] grafikleri kullanılarak hesaplandı. Metil benzoilsülfamat, Metil (2-bromobenzoil) sülfamat, Metil (3fenilpropanoil) sülfamat, Metil (1-naphthoil) sülfamat, Metil (2metilbenzoil) sülfamat, Metil (2-iyodobenzoil) sülfamat, Metil (2fenilbutanoil) sülfamat, Metil (4-isopropilbenzoil) sülfamat, Metil (4-metoksibenzoil)sülfamat ve Metil (isoquinoline-1karbonil)sülfamat bileşikleri LPO enzimi inhibisyonunun $\mathrm{IC}_{50}$ değerleri sırası ile $33 \mu \mathrm{M}, 36,47 \mu \mathrm{M}, 23,89 \mu \mathrm{M}, 24,75 \mu \mathrm{M}, 69,3$ $\mu \mathrm{M}, 40,76 \mu \mathrm{M}, 53 \mu \mathrm{M}, 63 \mu \mathrm{M}, 43,31 \mu \mathrm{M}, 36,47 \mu \mathrm{M}$ bulunmuştur. Ki değerleri Lineweaver-Burk eğrileri kullanılarak hesaplanarak, Çizelge 1'de verilmiştir. Çizelge 1'de gösterildiği gibi, LPO enzimi için, Metil benzoilsülfamat, Metil (2-bromobenzoil)

\section{Sonuç}

Sonuç olarak, Metil benzoilsülfamat, Metil (2bromobenzoil) sülfamat, Metil (3-fenilpropanoil) sülfamat, Metil (1-naphthoil) sülfamat, Metil (2-metilbenzoil) sülfamat, Metil (2iyodobenzoil) sülfamat, Metil (2-fenilbutanoil) sülfamat, Metil (4-isopropilbenzoil) sülfamat, Metil (4-metoksibenzoil) sülfamat ve Metil (isoquinoline-1-karbonil) sülfamat bileşikleri LPO enziminin aktif bölgesine bağlanarak inhibisyona neden olmuştur. LPO enziminin biyosidal aktivitesi, katalize ettiği kimyasal reaksiyonların ürünlerinden kaynaklanmaktadır. Reaksiyonun ana ürünü olan hipotiyosiyanat, çeşitli proteinlerin tiyol grupları ile etkileşime girer ve bu da patojenlerin hayatta kalması için önemli bir role sahiptir. LPO enziminin bakteriler üzerindeki etkisi, sülfhidrilin oksidasyonundan önegelir. $-\mathrm{SH}$ gruplarının oksidasyonu bakteriyel sitoplazmik zarın glikoz, potasyum iyonları, amino asitler ve peptidleri taşıma yeteneğini kaybetmesine neden olur. Bu çalışma gösteriyor ki bu sülfamat bileşikleri LPO enziminin aktvitesini azaltmaktadır. LPO enziminin aktivitesi ve tiyosiyanat bileşimi laktasyon periyodunda önemlidir. Bundan dolayı LPO enzimi yenidoğanların bağışıklık sisteminde büyük rol oynar. $\mathrm{Bu}$ çalışmada kullanılan moleküllerden Metil benzoilsülfamat, Metil (2-bromobenzoil) sülfamat, Metil (3-fenilpropanoil) sülfamat, Metil (1-naphthoil) sülfamat, Metil (2-metilbenzoil) sülfamat, Metil (2-iyodobenzoil) sülfamat, Metil (2-fenilbutanoil) sülfamat, Metil (4-isopropilbenzoil) sülfamat, Metil (4-metoksibenzoil) sülfamat ve Metil (isoquinoline-1-karbonil) sülfamat bileşikleri yap1 itibari ile daha fazla sulfon, amid ve -OR grubuna sahiptir ve LPO enzimini daha iyi inhibe ettiği görülmektedir. Bu ise enzim aktivitesinin azalması immun sistemin zayıflaması anlamına gelmektedir. Anti-kanser tedavisinde, antiflemetuar, sülfamat, Metil (3-fenilpropanoil) sülfamat, Metil (1-naphthoil) sülfamat, Metil (2-metilbenzoil) sülfamat, Metil (2-iyodobenzoil) sülfamat, Metil (2-fenilbutanoil) sülfamat, Metil (4isopropilbenzoil) sülfamat, Metil (4-metoksibenzoil) sülfamat ve Metil (isoquinoline-1-karbonil) sülfamat bileşikleri maddeleri Ki sabitleri $0,018 \pm 0,0041 \mu \mathrm{M}$ ile $0,70 \pm 0,070 \mu \mathrm{M}$ aralığındaydı. Metil benzoilsülfamat, Metil (2-bromobenzoil) sülfamat, Metil (3-fenilpropanoil) sülfamat, Metil (1-naphthoil) sülfamat, Metil (2-metilbenzoil) sülfamat, Metil (2-iyodobenzoil) sülfamat, Metil (4-isopropilbenzoil) sülfamat, Metil (4-metoksibenzoil) sülfamat ve Metil (isoquinoline-1-karbonil) sülfamat bileşikleri yarışmalı inhibisyon Metil (2-fenilbutanoil) sülfamat yarışmasız inhibisyon etkisi göstermiştir. Bilindiği üzere sülfamatlar, sulfon grubuna amin ve -OR grubunun bağlı olan bileşiklerdir (Atmaca 2019). Bu çalışmadan kinetik sonuçlar ( $\mathrm{IC}_{50}$ ve Ki) incelendiğinde görülüyor ki Metil benzoilsülfamat, Metil (2-bromobenzoil) sülfamat, Metil (3-fenilpropanoil) sülfamat, Metil (1-naphthoil) sülfamat, Metil (2-metilbenzoil) sülfamat, Metil (2-iyodobenzoil) sülfamat, Metil (2-fenilbutanoil) sülfamat, Metil (4-isopropilbenzoil) sülfamat, Metil (4-metoksibenzoil) sülfamat ve Metil (isoquinoline-1karbonil) sülfamat bileşikleri sütü inhibe etmiştir. Metil benzoilsülfamat, Metil (2-bromobenzoil)sülfamat, Metil (3fenilpropanoil)sülfamat, Metil (1-naphthoil)sülfamat, Metil (2metilbenzoil)sülfamat, Metil (2-iyodobenzoil)sülfamat, Metil (2fenilbutanoil)sülfamat, Metil (4-isopropilbenzoil)sülfamat, Metil (4-metoksibenzoil)sülfamat ve Metil (isoquinoline-1karbonil)sülfamat bileşikleri için $\mathrm{Ki}$ sonuçları kıyaslandığında LPO enziminin en güçlü inhibitörü Metil (3fenilpropanoil)sülfamat bileşiğinin olduğu görülmüştür ve 0,018 $\pm 0,0041 \mu \mathrm{M}$ seviyede inhibe ettiği bulunmuştur.

antibakteriyel, antiviral vb. kullanılan ilaçların yapılarında bulunduğundan dolayı sülfamat bileşiklerin kullanımı emziren annelerin emzirme süreleri boyunca dikkat edilmelidir.

\section{Kaynakça}

Albright, J.D., Devries, V.G., Du, M.T., Largis, E.E., Miner, T.G., Reich, M.F., Shepherd, R.G. (1983). Potential antiatherosclerotic agents. 2. (Aralkylamino)- and (alkylamino)benzoic acid analogs of cetaben J. Med. Chem. $261393 \mathrm{e} 1411$.

Atamer M, Kocak C, Cimer A, Odabasi S, Tamucay B, Yamaner N. (1999). Some quality characteristics of Kasar cheese manufactured from milk preserved by activation of lactoperoxidase/thiocyanate/hydrogen peroxide (LP) system. Milchwissenschaft, 54: 553-556.

Atmaca, U. (2019). Efficient and one-pot synthesis of novel sulfamates from carboxylic acids. Tetrahedron 75 (34), 130467.

Atmaca, U. (2020) Tek Kapta Yeni Bir Yöntemle Alkollerden Potansiyel Biyolojik Aktif Azidosülfonil Bileşiklerinin Sentezi. Journal of the Institute of Science and Technology. 0(1): 345-356.

Berg, J.M., Tymoczko, J.L., Stryer, L. (2014). Biyokimya. Palme Yayıncılık, 241-247p, Ankara.

Booth, KS, Kimura, S., Lee, HC., Ikeda-Saito, M., \& Caughey, WS. (1989). Bovine myeloperoxidase and lactoperoxidase each contain a high affinity binding site for calcium. Biochemical and Biophysical Research Communications. $160,879 \pm 902$.

Champe, P.C., Harvey, R.A., Ferrier, D.R. (2007). Lippincott's lllustrated Reviews Serisinden: Biyokimya. Nobel Tip Kitapevleri, Bursa 
Daryadel S, Atmaca U, Taslimi P, Gulcin I, Celik M. (2018). Novel sulfamate derivatives of menthol: Synthesis, characterization, and cholinesterases and carbonic anhydrase enzymes inhibition properties. Archiv Der Pharmazie. 351.

Davies, KJ. (1995). Oxidative stress: the paradox of aerobic life. Biochem Soc Symp.61:1-31.

de Wit JN, van Hooydonk ACM. (1996). Structure, functions and applications of lactoperoxidase in natural antimicrobial systems. Netherlands Milk \& Dairy Journal. 50: 227 \pm 244 .

Demir Y, Beydemir Ş. (2015). Purification, refolding, and characterization of recombinant human paraoxonase-1. Turkish Journal of Chemistry. 39(4): 764-776.

Elagamy, E., Ruppanner, R., Ismail, A., Champagne, C.P., and Assal, R. (1992). Antibacterial and antiviral activity of camel milk protective proteins. J. Dairy. Res. 59, 169-175.

Goddard-Borger ED, Stick RV. (2007). An efficient, inexpensive, and shelf-stable diazotransfer reagent: Imidazole-1-sulfonyl azide hydrochloride. Organic Letters. 9: 3797-800

Gulcin I, Mshvildadze V, Gepdiremen A, Elias R. (2006). Screening of antioxidant and antiradical activity of monodesmosides and crude extract from Leontice smirnowii Tuber. Phytomedicine. 13: 343-351.

Haddain MS, Ibrahim SA, Robinson RK. (1996). Preservation of raw milk by activation of the natural lactoperoxidase systems. Food Control. 7: 149-152.

Gülçin, İ., Kirecci, E., Akkemik, E., Topal, F., Hisar, O. (2010a). Antioxidant and Antimicrobial Activities of an Aquatic Plant: Duckweed (Lemna minor L.). Turkish Journal of Agriculture and Forestry. 34, 175-188.

Haddain, M.S., İbrahim, S.A., and Robinson, R.K. (1996). Preservation of raw milk by activation of the natural lactoperoxidase systems. Food Control. 7, 149-152.

Hartwig JF. (1998). Carbon-heteroatom bond-forming reductive eliminations of amines, ethers, and sulfides. Accounts of Chemical Research. 31: 852-60.

Hussain S, Slikker W, Ali SF. (1995). Age related changes in antioxidant enzymes, superoxide dismutase, catalase, glutathione peroxidase and glutathione in different region of mouse brain. International Journal of Developmental Neuroscience.13: 811-817.

Ilardi, E.A. Vitaku, E. Njardarson, J.T. (2014). J. Med. Chem. 57, $2832 \mathrm{e} 2842$.

Jacob BM, Monoj NK, Haridas M. (1998). Antibacterial property of goat milk lactoperoxidase. Indian Journal of Experimental Biology. 31: 808 .

Kumar R, Bhatla KL. (1995). Purification, crystallization and preliminary X-ray crystallographic analysis of lactoperoxidase from buffalo milk. Acta Crystallographica. 51: 1094.

Kussendrager KD, van Hooijdonk ACM. (2000). Lactoperoxidase: physico-chemical properties, occurrence, mechanism of action and applications. British Journal of Nutrition. 84: 19-25.

Lehninger, A.L., Nelson, D.L., Cox, M.M. (2005). Principles of biochemistry, 3. Baskıdan çeviri (Çeviri editörü: Kılıç N.), Palme Yayıncilık.

Llaverias, G., Laguna, J.C. Alegret, M. Cardiovasc. (2003) Drug Rev. 21, 33e 50

Paul, K.G., and Ohlsson, P.I. (1985). In the Lactoperoxidase System: Pruitt KM, and Tenovue YO, (Eds.) Chemistry and Biological Significance, New York, USA: Marcel Dekker Inc. p.15-29.
Peterson, E.M., Brownell, J., Vince, R. (1992). J. Med. Chem. 35, $3991 \mathrm{e} 4000$.

Pütter, J., and Becker, R. (1987), Methods of Enzymatic Analysis: Peroxidases Bergmeyer, third edition, VCH ,New York, s.286.

Reiter, B., \& HaÈrnulv, G. (1984). Lactoperoxidase antibacterialsystem: natural occurrence, biological functions and practical applications. Journal of Food Protection, 47, $724 \pm 732$

Reiter, B., \& Perraudin, JP. (1991). Lactoperoxidase: biological functions. In Peroxydases in Chemistry and Biology. pp. 143 \pm 180. Boca Raton: CRC Press.

Sharma, S., Singh, A. K., Kaushik, S., Sinha, M., Singh, R. P., et al. (2013). Lactoperoxidase structural insights into the function, ligand binding and inhibition. International journal of biochemistry and molecular biology. 4(3), 108.

Shindler, J.S., and Bardsley, W.G. (1975). Steady-state kinetics of lactoperoxidase with ABTS as chromogen. Biochem. and Biophys. Res. Comm. 67, 1307.

Sisecioğlu M, Cankaya M, Ozdemir H. (2009). Effects of some vitamins on lactoperoxidase enzyme activity. International Journal for Vitamin and Nutrition Research . 79: 188-194.

Sisecioglu, M., Gulcin, I., Cankaya, M., Atasever, A., \& Ozdemir, H. (2010). The effects of norepinephrine on lactoperoxidase enzyme. Scientific Research and Essays. 5,1351-1356.

Thanabal, V., \& La Mar, GN. (1989) A nuclear Overhauser effect investigation of the molecular and electronic structure of the heme crevice in lactoperoxidase. Biochemistry, 28, $7038 \pm 7044$

Uguz, M.T., \& Ozdemir, H. (2005). Purification of bovine milk lactoperoxidase and nvestigation of antibacterial properties at different thiocyanate mediated. Applied. Biochemistry andMicrobiology. 41, 397-401.

Van Huystee, R.B. (1987). Some moleculer aspects of plant peroxidase biosynthetic studies. Ann. Rev. Plant. Physiol, 38, 205.

Wolfson, LM., \& Sumner, SS. (1993). Antimicrobial activity of the lactoperoxidase system. A review. Journal of Food Protection. 56, $887 \pm 892$. 